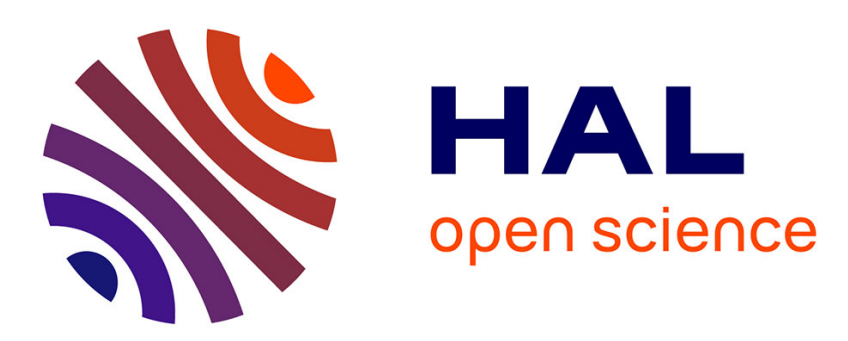

\title{
Screening Beyond Postpartum Depression: Occluded Anxiety Component in the EPDS (EPDS-3A) in French Mothers
}

Déborah Loyal, Anne-Laure Sutter-Dallay, Nicole Rascle

\section{- To cite this version:}

Déborah Loyal, Anne-Laure Sutter-Dallay, Nicole Rascle. Screening Beyond Postpartum Depression: Occluded Anxiety Component in the EPDS (EPDS-3A) in French Mothers. Maternal and Child Health Journal, 2020, 24 (3), pp.369-377. 10.1007/s10995-020-02885-8 . hal-03131567

\author{
HAL Id: hal-03131567 \\ https://hal.science/hal-03131567
}

Submitted on 16 Dec 2021

HAL is a multi-disciplinary open access archive for the deposit and dissemination of scientific research documents, whether they are published or not. The documents may come from teaching and research institutions in France or abroad, or from public or private research centers.
L'archive ouverte pluridisciplinaire HAL, est destinée au dépôt et à la diffusion de documents scientifiques de niveau recherche, publiés ou non, émanant des établissements d'enseignement et de recherche français ou étrangers, des laboratoires publics ou privés. 


\title{
Screening Beyond Postpartum Depression:
}

\section{Occluded Anxiety Component in the EPDS (EPDS-3A) in French Mothers}

\section{Loyal, A.-L. Sutter \& N. Rascle}

\begin{abstract}
Introduction. According to many studies, anxiety in the perinatal period is widespread and has many detrimental effects. Thus, screening measures should not be limited to assessing depression symptoms. The widely used Edinburgh Postnatal Depression Scale (EPDS) might assess depression but also anxiety symptoms. This study explores whether an anxiety dimension (EPDS-3A) was found and valid in French women during pregnancy and the postpartum period.

Methods. French women were followed-up at late pregnancy and 2 and 4 months postpartum $(\mathrm{N}=144,138$ and 129). They completed the EPDS and the Hospital Anxiety and Depression Scale (HADS-A). Exploratory factor analyses were performed. Then to test its validity, the EPDS-3A was correlated with anxiety (HADS-A) and depression (EPDS-D) scores. Finally, prevalence estimates were computed according to recommended cut off.

Results. The anxiety dimension assessed through the EPDS-3A was observed during the postpartum period but not during pregnancy. A two-factor structure (depression and anxiety) increases the variance explained at 2 and 4 months postpartum (respectively 6 and 12\%). The EPDS-3A shows good internal consistency ( $\geq .70)$ and was more strongly associated with anxiety scores (HADS-A) (.48-.57) than with depression scores (EPDS-D) (.30-.39). Nearly $28 \%$ of mothers had scores that exceeded the EPDS-3A cut off ( $\geq 4)$ but not the full EPDS cut off ( $\geq 13$ or more).
\end{abstract}

Discussion: The EPDS contains an anxiety component (EPDS-3A) that can be found in French women during the postnatal period but not during pregnancy. It shows signs of internal consistency and validity. The EPDS-3A could be considered when screening for postpartum anxiety.

Keywords: Anxiety symptoms; Depression symptoms; Edinburgh Postnatal Depression Scale; Postpartum; Pregnancy 
Significance: In mothers-to-be and new mothers, anxiety is widespread and has many detrimental effects. Some studies suggest that the widely used Edinburgh Postnatal Depression Scale (EPDS) could assess depression symptoms but also anxiety symptoms. Our results support the existence of an anxiety dimension in the EPDS (EPDS-3A) found during the postpartum but not during pregnancy. This anxiety subscale shows signs of internal consistency and validity. In the future, the EPDS-3A could considered to screen for postpartum anxiety. 


\section{Introduction}

Postpartum depression is a debilitating condition seen in $13-19 \%$ of women giving birth (O’Hara \& Swain, 1996) that may have major consequences for children such as psychopathological disorders, impaired cognitive development, and insecure attachment (O'Hara \& McCabe, 2013). This condition is linked to strong risk factors, such as a past history of depression and symptoms of anxiety and depression during pregnancy. Other risk factors have been described such as low social support, low socioeconomic status, personality traits, and perinatal complications (Robertson, Grace, Wallington, \& Stewart, 2004). Furthermore, 12-18\% of women are suffering from depression while pregnant (Bennett, Einarson, Taddio, Koren, \& Einarson, 2004). Antenatal depression has been associated with poorer child development (Kingston, Tough, \& Whitfield, 2012) and obstetric issues (Grigoriadis et al., 2013).

Postpartum depression has been described for long as including prominent anxious features (Pitt, 1968). In new mothers and pregnant women, anxiety symptoms might even be more frequent than depression symptoms (Farr, Dietz, O'Hara, Burley, \& Ko, 2014). Anxiety in new mothers has been associated with child impaired cognitive development (Kingston et al., 2012) and emotional and behavioral troubles (Glasheen, Richardson, \& Fabio, 2010). Moreover, anxiety in pregnancy might be linked with negative obstetric issues (Alder, Fink, Bitzer, Hösli, \& Holzgreve, 2007). Thus, many scholars are arguing that depression symptoms should not be the only focus of attention when dealing with distressed mothers and mothers-to-be (Rallis, Skouteris, McCabe, \& Milgrom, 2014; WHO, 2009).

In view of this evidence, assessing anxiety in pregnant women and new mothers seems important. Moreover, depression and anxiety should be distinguished because they might have distinct prevalence rates, longitudinal course, and treatment (Rivas-Vazquez, Saffa-Biller, Ruiz, Blais, \& Rivas-Vazquez, 2004). In addition, comorbid symptoms of depression and anxiety are frequent and seem to be a sign of severity (Farr et al., 2014; Rivas-Vazquez et al., 2004). 
The most widely used instrument to assess depression symptoms in mothers and in pregnant women (Gibson, Mckenzie-Mcharg, Shakespeare, Price, \& Gray, 2009) is the Edinburgh Postnatal Depression Scale (EPDS) (Cox, Holden, \& Sagovsky, 1987). This scale contains 10 items with 4 possible responses (0-3). During pregnancy and the postpartum, cut off of 13 or more (major depression) and 10 or more (minor depression) are usually recommended (Cox et al., 1987; Gibson et al., 2009). The EPDS has been validated in various languages, shows good psychometric qualities (Gibson et al., 2009). and is well accepted by recipients (Brealey et al., 2010).

The EPDS is supposed to provide a one-dimensional measure of depression symptoms. However, some studies support a two-factor structure covering depression and anxiety. Items 3, 4 and 5 have been repeatedly found to load on an anxiety dimension (Matthey, Fisher, \& Rowe, 2013; Reichenheim, Moraes, Oliveira, \& Lobato, 2011). This dimension has been labelled EPDS-3A by Matthey et al. (2013). Some authors have suggested an EPDS-3A cut-off of 6 or more or 4 or more (Matthey et al., 2013).

Adding up all items of a multidimensional scale such as the EPDS could be unwarranted. Indeed, different dimensions might have various risk factors and consequences which would not be distinguishable if all items are summed up (Reichenheim et al., 2011). Thus, the structure of the EPDS should be explored, especially regarding the 3 items (items 3, 4 and 5) that might assess anxiety (EPDS-3A). Moreover, Items 6, 7 and 8 are often ill behaved (Reichenheim et al., 2011). Item 7 might be difficult to answer as women might have difficult time sleeping because of body changes and baby sleep patterns (Brealey, Hewitt, Green, Morrell, \& Gilbody, 2010). Moreover, item 10 might be poorly understood as it might be read as referring to unintentional injury, deliberate self-harm or suicide (Brealey et al., 2010).

The present study was designed to explore the structure of the EPDS in a sample of French women during pregnancy and the postpartum period. Items 3, 4 and 5 were expected to load on an anxiety dimension (EPDS-3A). The EPDS-3A was expected to exhibit convergent validity in comparison with another scale assessing anxiety. Prevalence estimates were also computed. 


\section{Methods}

\section{Procedure and Participants}

Pregnant women were recruited at the maternity ward of a local French university hospital during a mandatory information meeting about childbirth pain relief. Participants had to be fluent in French (spoken and written) and to be older than 18 years. They had to have no multiple pregnancy or medically assisted procreation because it might lead to anxiety and depression symptoms or obstetric complication (Fisher \& Stocky, 2003; Hammarberg, Fisher, \& Wynter, 2008).

During last trimester of pregnancy (T1) participants were received in an office of the maternity ward. They completed a set of self-administered questionnaires. Then, 2 months (T2) and 4 months (T3) after the birth, they were asked to answer self-administrated questionnaires online.

Informed consent was obtained during the last trimester of pregnancy (T1) from all individual participants included in the study. All participants were informed that they would be solicited three times and that they were free to stop their participation at any time. All procedures were in accordance with the ethical standards of the institutional and/or national research committee and with the 1964 Helsinki declaration and its later amendments. This study was approved by a national informatics right committee (https://www.cnil.fr/) and a regional ethic committee (http://www.cpp-soom3.ubordeaux2.fr/).

\section{Measures}

The French version of the EPDS (Cox et al., 1987; Guedeney \& Fermanian, 1998) was selfadministered. As said previously, it contains 10 items proposed with 4 possible responses rated from 0 to 3. Owing to Exploratory Factor Analyses results presented thereafter, in addition to the usual full EPDS score (all items), two scores have been computed to assess anxiety symptoms (EPDS-3A including items 3, 4 and 5) and depression symptoms (EPDS-D including items 1, 2, 7, 8, 9 and 10). Item 6 was dropped because of low loadings. 
The French validation of the Hospital Anxiety and Depression Scale or HADS (Lepine, Godchau, Brun, \& Lempérière, 1985; Zigmond \& Snaith, 1983) was used to measure anxiety symptoms. This self administrated scale contains 14 items assessing depression symptoms (7 items) and anxiety symptoms ( 7 items). Each item is offered with 4 possible responses rated from 0 to 3 . A two-factor structure is usually observed, but some scholars have observed other structure (Cosco, Doyle, Ward, \& McGee, 2012). To assess anxiety, Straat, Van Der Ark, \& Sijtsma (2013) have recommended to use 5 items (items 1, 2, 3, 5 and 7). Those 5 items have been used and this score will be referred as HADS-A. At each measurement time, the HADS-A had great internal consistencies $(>.70)$.

\section{Statistical analysis}

Exploratory Factor Analysis (EFA) was computed. Our sample size is sufficient to perform such an analysis (Costello \& Osborne, 2005). Principal Factor extraction and Oblimin rotation were chosen (Costello \& Osborne, 2005). Cut off for loading was >.40 (Costello \& Osborne, 2005). An anxiety dimension comprising items 3, 4 and 5 (EPDS-3A) was expected.

Secondly, Spearman correlations were computed to assess relations between anxiety scores (EPDS-3A and HADS-A) and depression score (EPDS-D). The EPDS-3A was expected to be associated more strongly anxiety scores (HADS-A) than with depression scores (EPDS-D).

In addition, prevalence have been estimated according to recommended cut off for the full EPDS ( $\geq 10$ or 13) and the EPDS-3A ( $\geq 4$ or 6). Finally, percentage of women whose scores exceeded the EPDS-3A cut-off but not the full EPDS cut-off have been estimated.

\section{Results}

\section{Descriptive Statistics}

Sample description is provided in Table 1. Participants $(\mathrm{T} 1, \mathrm{~N}=144)$ were on average 30.9 years old $(\mathrm{SD}=4.15)$. They were mostly born in France $(93.8 \%)$, well educated $(70.8 \%$ had $\geq 3$ years of post-secondary education) and working (80.6\%) at least 35 hours per week (88\%) in intermediate or 
highly skilled job (75\%). Most of them were engaged in a relationship (97.9\%). The sample includes mainly first-time mothers (72.9\%). Women who already had children had mostly one child $(84.6 \%)$ about 3 years old $(\mathrm{M}=37.5$ months, $\mathrm{SD}=18.86$ months $)$. For most participants the pregnancy was described as planned (84\%) and happily welcomed (82.6\%). Regarding major obstetric complications some participants have reported a complicated or emergency C-section (8.7\%) but none reported that the baby was born prematurely ( $>30$ days), underweighted $(<2 \mathrm{~kg})$ or put in an incubator ( $>4$ weeks).

\section{INSERT TABLE 1}

Some participants $(\mathrm{N}=15)$ were lost at follow up between the last trimester of pregnancy ( $\mathrm{T} 1$, $\mathrm{N}=144), 2$ months (T2, $\mathrm{N}=138)$ and 4 months postpartum (T3, $\mathrm{N}=129)$. Using Fisher Exact Test, it was estimated that they were more often born abroad $(20 \%$ vs. $4.7 \%, \mathrm{p}<.05)$ and less educated $(53.3 \%$ vs. $26.4 \%$ with $\leq 2$ years of post-secondary education, $\mathrm{p}<.05$ ). Many reported having an unplanned pregnancy $(53.3 \%$ vs $11.6 \%, \mathrm{p}<.01)$. Even if there is no established cut off for missing data, proportions lower than 5 or $10 \%$ are usually regarded as having few or no consequences (Bennett, 2001; Dong \& Peng, 2013).

\section{Exploratory Factor Analysis}

Scree plots (Figure 1) suggest that one strong factor might be extracted. However, a second factor might be extracted especially in T3 data. Extracting a third factor might not be insightful. EFA results regarding each measurement time are presented in Table 2, 3 and 4.

\section{INSERT FIGURE 1}

INSERT TABLE 2, 3 and 4.

Broadly speaking, a one-factor structure is satisfactory at T1, T2 and, to a lesser extent, at T3. However, choosing a two-factor structure rather than a one-factor structure increases substantially the variance explained at T1 $(+8 \%), \mathrm{T} 2(+6 \%)$ and especially at T3 $(+12 \%)$. A three-factor structure seems unsatisfactory mainly because it produces single item "dimensions" and even a Heywood case (T1). Moreover, it adds few explained variance. 
At T1 (Table 2) one should note that item 10 fails to load on any dimension irrespective of the number of dimension. The two-factor structure was comprised of a depression dimension (items 1, 2, 3, 6, 7, 8 and 9) and an anxiety dimension (items 4 and 5). In sum, 43\% of the variance was explained by depression $(31 \%)$ and anxiety $(12 \%)$. Internal consistencies were satisfactory for each dimension (>.70). However, the EPDS-3A (item 3, 4 and 5) was not observed.

At T2 (Table 3), the two-factor structure was comprised of a depression dimension (items 1, 2, 7, 8, 9 and 10) and the EPDS-3A anxiety dimension (items 3, 4 and 5). Item 6 fails to load on both dimensions. In sum, $45 \%$ of the variance was explained by depression (27\%) and anxiety (18\%). Internal consistencies were satisfactory for each dimension (>.70).

At T3 (Table 4), the two-factor structure was comprised of a depression dimension (items 1, 2, 7, 8, 9 and 10) and the EPDS-3A anxiety dimension (items, 3, 4 and 5). Item 6 fails to load on both dimensions. In sum $44 \%$ of the variance was explained by depression (29\%) and anxiety (15\%). Internal consistencies were satisfactory for each dimension (>.70).

\section{Convergent and Divergent Validity}

The expected anxiety dimension (EPDS-3A) was observed only in the postpartum (T2 and T3). Thus at T2 and T3, two scores were computed from the EDPS: the EPDS-D (items 1, 2, 7, 8, 9 and 10) and the EPDS-3A (items 3, 4 and 5). Item 6 was dropped because of low loadings.

Spearman correlations between each scores from the EPDS (EPDS-D and EPDS-3A) and the HADS-A were computed at T2 and T3. At T2, correlation between EPDS-3A and HADS-A (.57) was significantly higher than correlation between EPDS-3A and EPDS-D (.39) $(Z=-2.05, \mathrm{p}<.05)$ (Lee \& Preacher, 2013). Similarly, at T3, correlation between EPDS-3A and HADS-A (.48) was significantly higher than correlation between EPDS-3A and EPDS-D (.30) $(\mathrm{Z}=-1.87, \mathrm{p}<.05)$ (Lee \& Preacher, 2013). 


\section{Prevalence}

Regarding the full EPDS cut-off ( $\geq 13$ or 10 ) depression symptoms were higher at T2 (9.7$18.1 \%$ ) than at T3 (4.2-9.7\%). Regarding the EPDS-3A cut-off ( $\geq 6$ or 4 ) anxiety symptoms were also higher at $\mathrm{T} 2(13.2-36.1 \%)$ than at $\mathrm{T} 3(7.6-25 \%)$. There were also more women scoring high on both scales at $\mathrm{T} 2(7.3-17.5 \%)$ than at $\mathrm{T} 3(3.1-7.8 \%)$. Resultst are provided in Table 5.

\section{INSERT TABLE 5}

Moreover, many women scoring high on the EPDS-3A were not detected by the full EPDS. When using a low EPDS-3A cut-off $(\geq 4)$, many anxious women were not detected by the full EPDS cut-off at T2 (19.7-27.7\% with respectively $\geq 13$ and $\geq 10)$ and $\mathrm{T} 3(20.2-24.8 \%$ with respectively $\geq 13$ and $\geq 10)$. When using a higher EPDS-3A cut-off $(\geq 6)$, some anxious women were not detected by the full EPDS cut-off at T2 (1.5-5.8\% with respectively $\geq 13$ and $\geq 10)$ and T3 (3.1-5.4\% with respectively $\geq 13$ and $\geq 10$ ). Resultst are provided in Table 6 .

\section{INSERT TABLE 6}

\section{Discussion}

The expected anxiety dimension (EPDS-3A), including items, 3, 4 and 5, was only observed during the postpartum period but not during pregnancy. Thus our first hypothesis regarding the EPDS$3 \mathrm{~A}$ was partly confirmed.

As expected, item 4 and 5 were continuously loading on an anxiety factor. However item 3 , which was supposed to assess anxiety (Matthey et al., 2013; Reichenheim et al., 2011) was loading on an anxiety factor during the postpartum but was loading on a depression factor during pregnancy. Item 3 is explicitly referring to self-blame which is a well-known component of depression (Beck, 1967). It remains unclear why such a result was obtained during pregnancy but not during the postpartum period. Maybe pregnant women and new mothers are not referring to the same "things" when they answer item 3 ("I have blamed myself unnecessarily when things went wrong"). Indeed, stressors experienced by pregnant women and new mothers might be different (DiPietro, Ghera, Costigan, \& 
Hawkins, 2004; Jevitt, Groer, Crist, Gonzalez, \& Wagner, 2012). Furthermore, item 6 was ill-adapted, especially during the postpartum when it fails to load on depression or anxiety dimensions. This item might be poorly adapted to cover either anxiety or depression. Items 7 and 8 which had been previously identified as ill-behaved (Reichenheim et al., 2011) were quite robust in our analysis. Those items were loading clearly on a depression dimension. Item 10 fails to load on any dimensions during pregnancy. Our guess is that this item might be poorly understood as it might be read as referring to unintentional injury, deliberate self-harm or suicide (Brealey et al., 2010). This problem might be especially true in pregnant women who might fear hurting themselves and their unborn child by accident. In sum, questions were raised regarding some items: item 3 might assess depression rather than anxiety in pregnant women, item 6 might assess poorly either anxiety or depression and item 10 might be ambiguous especially for pregnant women.

As expected, it was observed that the anxiety dimension assessed through the EPDS-3A was more strongly correlated with the HADS-A than with the EPDS-D. This stronger correlation is indicative of its convergent validity. Our second hypothesis stating that the EPDS-3A would exhibit convergent validity was confirmed during the postpartum period.

In accordance with many studies (Farr et al., 2014; Grant, McMahon, \& Austin, 2008), anxiety symptoms seem to be more prevalent than depression symptoms in new mothers. Moreover, anxiety and depression symptoms might be more prevalent at 2 months postpartum than at 4 months postpartum. This higher prevalence during the early postpartum has been observed previously regarding depression (Moss, Skouteris, Wertheim, Paxton, \& Milgrom, 2009) but not regarding anxiety which is rather found to grow stronger through the postpartum (Moss et al., 2009). Our results also highlight that when using the full EPDS score one does not screen efficiently for women with high anxiety symptoms (EPDS-3A). Many new mothers (up to 28\%) are exhibiting anxiety symptoms (EPDS-3A) and are not screened by the EPDS scored as a whole.

However, one should note that the EPDS-3A items (items 3, 4 and 5) share a common formulation indicating a judgment about one's own feelings ("unnecessarily", "for no good reason" 
and "for no very good reason") (Brouwers, Van Baar, \& Pop, 2001). This formulation might produce an artificial dimension. Moreover, the EPDS-3A does not include items about somatic symptoms which are important in anxiety (Brouwers et al., 2001). Some authors argue that such symptoms should not be considered because they might be confounded with normal somatic symptoms occurring after birth (O'Hara \& McCabe, 2013). Nevertheless, depressed or anxious new mothers (Woolhouse, Gartland, Perlen, Donath, \& Brown, 2014) and pregnant women (Yonkers, Smith, Gotman, \& Belanger, 2009) are experiencing higher somatic symptoms. Thus, somatic symptoms should not be dismissed as trivial. Our guess is that scales should, in addition to emotional items, include somatic items and conduct analysis to determine appropriate cut-off for such scores. The presence of somatic symptoms only could be considered as not indicative of anxiety. Finally, the EPDS-3A performance to screen for women with perinatal anxiety disorders remains ambiguous (Fairbrother, Corbyn, Thordarson, Ma, \& Surm, 2019; Matthey et al., 2013). Our guess is that this scale might undergo substantial improvements (Fairbrother et al., 2019).

The EPDS itself should be considered with caution. This scale is widely used in new mothers and, to a lesser extent, in pregnant women (Gibson et al., 2009). However, it does not contain item about pregnancy, childbirth, child or childcare, although studies have showed that new mothers are experiencing specific stressors and anxieties (Phillips, Sharpe, Matthey, \& Charles, 2009). Some interesting scales have been designed to assess specific anxieties during pregnancy (child health, childbirth and one own physical attractiveness) (Reymond, Derguy, Wendland, \& Loyal, 2019) and after birth (maternal competence, infant safety, childcare and personal adjustment to motherhood) (Fallon, Halford, Bennett, \& Harrold, 2016).

This study has many strengths. First, to our knowledge, it is the first to explore the EPDS-3A in a sample of French women. Moreover, its longitudinal design has made it possible to search for the EPDS-3A in both the postpartum period ( 2 and 4 months) and the last trimester of pregnancy, which has never been done before. Finally, our sample size was adequate to conduct EFA under proper conditions (Costello \& Osborne, 2005). However, this study suffers some limitations. First, participants answered self-administrated scales after a face-to-face interview in late pregnancy (T1) 
and online after the birth (T2 and T3). This study was designed this way to ease participation and ensure a low attrition rate. Secondly, our participants were privileged women, educated and engaged in skilled jobs. However, using a recommended cut-off to assess major and minor depression episode (EPDS $\geq 10$ ) (Gibson et al., 2009) we get prevalence of $18.1 \%$ at 2 months postpartum and $9.7 \%$ at 4 months postpartum. These prevalence are similar to those observed in the literature with the EPDS (O’Hara \& McCabe, 2013; O’Hara \& Swain, 1996). The correlation between symptoms of depression (EPDS-D) and anxiety (EPDS-3A) was found to be quite moderate in our sample (.30-.39). One can expect that this association could be stronger in a population with a higher prevalence of both troubles. One should note that in our sample at 2 months postpartum, a sizeable number of women were exhibiting comorbid anxious and depressive symptoms (7.3-17.5\%). Further research should consider using confirmatory factor analysis to establish model fit for one-dimensional and bi-dimensional models. Moreover, our guess is that future studies about the EPDS-3A should include both generic measures of anxiety and depression symptoms and specific measures assessing specific worries occurring during pregnancy and after birth.

Our results highlight that the EPDS has an occluded anxiety component (EDPS-3A). However, the anxiety dimension assessed through the EPDS-3A was observed during the postpartum period but not during pregnancy. The EPDS-3A showed good internal consistency and convergent validity. To our knowledge it is the first French study to test the existence of an occluded anxiety component in the EPDS during pregnancy and the postpartum. The EPDS, is the most frequently used instrument, it is brief, has been extensively validated (Gibson et al., 2009) and is well accepted by recipients (Brealey et al., 2010). Further research might explore more fully the clinical relevance of scoring separately the anxiety dimension (EPDS-3A) of the EPDS. Indeed, it is essential to distinguish depression and anxiety symptoms because they have a distinct pattern in terms of prevalence rates, symptom profile, longitudinal course, and response to treatment (Rivas-Vazquez et al., 2004). Moreover, identifying women who score high on both depression and anxiety might help screening the most vulnerable ones (Farr et al., 2014).

Conflict of interest: the authors declare that they have no conflict of interest. 


\section{References}

Alder, J., Fink, N., Bitzer, J., Hösli, I., \& Holzgreve, W. (2007). Depression and anxiety during pregnancy : A risk factor for obstetric, fetal and neonatal outcome? A critical review of the literature. The Journal of Maternal-Fetal \& Neonatal Medicine, 20(3), 189- 209. https://doi.org/10.1080/14767050701209560

Beck, A. T. (1967). Depression : Clinical, Experimental, and Theoretical Aspects. University of Pennsylvania Press.

Bennett, D. A. (2001). How can I deal with missing data in my study? Australian and New Zealand Journal of Public Health, 25(5), 464- 469.

Bennett, H. A., Einarson, A., Taddio, A., Koren, G., \& Einarson, T. R. (2004). Prevalence of depression during pregnancy: Systematic review. Obstetrics \& Gynecology, 103(4), 698- 709. https://doi.org/10.1097/01.AOG.0000116689.75396.5f

Brealey, S. D., Hewitt, C., Green, J. M., Morrell, J., \& Gilbody, S. (2010). Screening for postnatal depression - is it acceptable to women and healthcare professionals? A systematic review and meta- synthesis. Journal of Reproductive and Infant Psychology, 28(4), 328- 344. https://doi.org/10.1080/02646838.2010.513045

Brouwers, E. P. M., Van Baar, A. L., \& Pop, V. J. M. (2001). Does the Edinburgh Postnatal Depression Scale measure anxiety? Journal of psychosomatic research, 51(5), 659- 663.

Cosco, T. D., Doyle, F., Ward, M., \& McGee, H. (2012). Latent structure of the Hospital Anxiety And Depression Scale : A 10-year systematic review. Journal of Psychosomatic Research, 72(3), 180- 184. https://doi.org/10.1016/j.jpsychores.2011.06.008

Costello, A. B., \& Osborne, J. W. (2005). Best Practices in Exploratory Factor Analysis : Four Recommendations for Getting the Most From Your Analysis. Practical Assessment, Research \& Evaluation, 10, 173-178.

Cox, J. L., Holden, J. M., \& Sagovsky, R. (1987). Detection of postnatal depression : Development of the 10-item Edinburgh Postnatal Depression Scale. British journal of psychiatry, 150, 782- 786. https://doi.org/10.1192/bjp.150.6.782 
DiPietro, J. A., Ghera, M. M., Costigan, K., \& Hawkins, M. (2004). Measuring the ups and downs of pregnancy stress. Journal of Psychosomatic Obstetrics \& Gynecology, 25(3- 4), 189- 201. https://doi.org/10.1080/01674820400017830

Dong, Y., \& Peng, C.-Y. J. (2013). Principled missing data methods for researchers. SpringerPlus, 2. https://doi.org/10.1186/2193-1801-2-222

Fairbrother, N., Corbyn, B., Thordarson, D. S., Ma, A., \& Surm, D. (2019). Screening for perinatal anxiety disorders : Room to grow. Journal of Affective Disorders, 250, 363- 370. https://doi.org/10.1016/j.jad.2019.03.052

Fallon, V., Halford, J. C. G., Bennett, K. M., \& Harrold, J. A. (2016). The Postpartum Specific Anxiety Scale : Development and preliminary validation. Archives of Women's Mental Health, 19(6), 1079- 1090. https://doi.org/10.1007/s00737-016-0658-9

Farr, S. L., Dietz, P. M., O’Hara, M. W., Burley, K., \& Ko, J. Y. (2014). Postpartum anxiety and comorbid depression in a population-based sample of women. Journal of Women's Health, 23(2), 120- 128. https://doi.org/10.1089/jwh.2013.4438

Fisher, J., \& Stocky, A. (2003). Maternal perinatal mental health and multiple births : Implications for practice. Twin Research, 6(06), 506-513. http://dx.doi.org/10.1375/136905203322686509

Gibson, J., Mckenzie-Mcharg, K., Shakespeare, J., Price, J., \& Gray, R. (2009). A systematic review of studies validating the Edinburgh Postnatal Depression Scale in antepartum and postpartum women. Acta psychiatrica Scandinavica, 119(5), 350- 364. https://doi.org/10.1111/j.16000447.2009.01363.x

Glasheen, C., Richardson, G. A., \& Fabio, A. (2010). A systematic review of the effects of postnatal maternal anxiety on children. Archives of Women's Mental Health, 13(1), 61- 74. https://doi.org/10.1007/s00737-009-0109-y

Grant, K. A., McMahon, C., \& Austin, M. P. (2008). Maternal anxiety during the transition to parenthood: A prospective study. Journal of Affective Disorders, 108(1- 2), 101- 111. https://doi.org/10.1016/j.jad.2007.10.002

Grigoriadis, S., VonderPorten, E. H., Mamisashvili, L., Tomlinson, G., Dennis, C.-L., Koren, G., ... Ross, L. E. (2013). The Impact of Maternal Depression During Pregnancy on Perinatal 
Outcomes : A Systematic Review and Meta-Analysis. The Journal of Clinical Psychiatry, 74(04), e321- e341. https://doi.org/10.4088/JCP.12r07968

Guedeney, N., \& Fermanian, J. (1998). Validation study of the French version of the Edinburgh Postnatal Depression Scale (EPDS) : New results about use and psychometric properties. European Psychiatry, 13(2), 83- 89. https://doi.org/10.1016/S0924-9338(98)80023-0

Hammarberg, K., Fisher, J. R. W., \& Wynter, K. H. (2008). Psychological and social aspects of pregnancy, childbirth and early parenting after assisted conception : A systematic review. Human Reproduction Update, 14(5), 395- 414. https://doi.org/10.1093/humupd/dmn030

Jevitt, C. M., Groer, M. W., Crist, N. F., Gonzalez, L., \& Wagner, V. D. (2012). Postpartum Stressors : A Content Analysis. Issues in Mental Health Nursing, 33(5), 309- 318. https://doi.org/10.3109/01612840.2011.653658

Kingston, D., Tough, S., \& Whitfield, H. (2012). Prenatal and Postpartum Maternal Psychological Distress and Infant Development : A Systematic Review. Child Psychiatry \& Human Development, 43(5), 683- 714. https://doi.org/10.1007/s10578-012-0291-4

Lee, I. A., \& Preacher, K. J. (2013). Calculation for the test of the difference between two dependent correlations with one variable in common Available from http://quantpsy.org. Consulté à l'adresse http://quantpsy.org/corrtest/corrtest2.htm

Lepine, J. P., Godchau, M., Brun, P., \& Lempérière, T. (1985). Evaluation of anxiety and depression among patients hospitalized on an internal medicine service. Annales Médico-Psychologiques, 143(2), 175- 189.

Matthey, S., Fisher, J., \& Rowe, H. (2013). Using the Edinburgh postnatal depression scale to screen for anxiety disorders : Conceptual and methodological considerations. Journal of Affective Disorders, 146(2), 224- 230. https://doi.org/10.1016/j.jad.2012.09.009

Moss, K. M., Skouteris, H., Wertheim, E. H., Paxton, S. J., \& Milgrom, J. (2009). Depressive and anxiety symptoms through late pregnancy and the first year post birth : An examination of prospective relationships. Archives of Women's Mental Health, 12(5), 345- 349. https://doi.org/10.1007/s00737-009-0086-1 
O'Hara, M. W., \& McCabe, J. E. (2013). Postpartum depression : Current status and future directions. Annual Review of Clinical Psychology, 9, 379- 407. https://doi.org/10.1146/annurev-clinpsy050212-185612

O’Hara, M. W., \& Swain, A. M. (1996). Rates and risk of postpartum depression : A meta-analysis. International Review of Psychiatry, 8(1), 37. https://doi.org/10.3109/09540269609037816

Phillips, J., Sharpe, L., Matthey, S., \& Charles, M. (2009). Maternally focused worry. Archives of Women's Mental Health, 12(6), 409- 418. https://doi.org/10.1007/s00737-009-0091-4

Pitt, B. (1968). « Atypical » depression following childbirth. The British Journal Of Psychiatry: The Journal Of Mental Science, 114(516), 1325- 1335.

Rallis, S., Skouteris, H., McCabe, M., \& Milgrom, J. (2014). The transition to motherhood : Towards a broader understanding of perinatal distress. Women and Birth, 27(1), 68- 71. https://doi.org/10.1016/j.wombi.2013.12.004

Reichenheim, M. E., Moraes, C. L., Oliveira, A. S. D., \& Lobato, G. (2011). Revisiting the dimensional structure of the Edinburgh Postnatal Depression Scale (EPDS) : Empirical evidence for a general factor. BMC Medical Research Methodology, 11, 93. https://doi.org/10.1186/1471-2288-11-93

Reymond, C., Derguy, C., Wendland, J., \& Loyal, D. (2019). Validation française d'une échelle d'anxiété spécifique à la grossesse (PRAQ-R2). /data/revues/12691763/unassign/S1269176318301044/. Consulté à l'adresse https://www.emconsulte.com/en/article/1270049

Rivas-Vazquez, R. A., Saffa-Biller, D., Ruiz, I., Blais, M. A., \& Rivas-Vazquez, A. (2004). Current issues in anxiety and depression: Comorbid, mixed, and subthreshold disorders. Professional Psychology: Research and Practice, 35(1), 74- 83. https://doi.org/10.1037/0735-7028.35.1.74

Robertson, E., Grace, S., Wallington, T., \& Stewart, D. E. (2004). Antenatal risk factors for postpartum depression: A synthesis of recent literature. General hospital psychiatry, 26(4), 289- 295. 
Straat, J. H., Van Der Ark, L. A., \& Sijtsma, K. (2013). Methodological artifacts in dimensionality assessment of the Hospital Anxiety and Depression Scale (HADS). Journal of Psychosomatic Research, 74(2), 116- 121. https://doi.org/10.1016/j.jpsychores.2012.11.012

WHO. (2009). Mental Health Aspects of Women's Reproductive Health: A Global Review of the Literature. Geneva: World Health Organization.

Woolhouse, H., Gartland, D., Perlen, S., Donath, S., \& Brown, S. J. (2014). Physical health after childbirth and maternal depression in the first 12 months post partum : Results of an Australian nulliparous pregnancy cohort study. Midwifery, 30(3), 378- 384. https://doi.org/10.1016/j.midw.2013.03.006

Yonkers, K. A., Smith, M. V., Gotman, N., \& Belanger, K. (2009). Typical somatic symptoms of pregnancy and their impact on a diagnosis of major depressive disorder. General Hospital Psychiatry, 31(4), 327- 333. https://doi.org/10.1016/j.genhosppsych.2009.03.005

Zigmond, A. S., \& Snaith, R. P. (1983). The Hospital Anxiety and Depression Scale. Acta Psychiatrica Scandinavica, 67(6), 361- 370. https://doi.org/10.1111/j.16000447.1983.tb09716.x 
Table 1. Participants Characteristics during Pregnancy $(\mathrm{T} 1, \mathrm{~N}=144)$

\begin{tabular}{|c|c|}
\hline Variable & $M(S D)$ or $\%$ \\
\hline Age (years) & $30.9(4.15)$ \\
\hline Born in France & $93.75 \%$ \\
\hline Engaged in a relationship & $97.9 \%$ \\
\hline First time mother & $72.9 \%$ \\
\hline Previous child & $27.1 \%$ \\
\hline One child & $84.6 \%$ \\
\hline Youngest child age (months) & $37.51(18.86)$ \\
\hline$\geq 3$ years post-secondary Education & $70.8 \%$ \\
\hline \multicolumn{2}{|l|}{ Skill Level } \\
\hline White collar / highly qualified & $41.1 \%$ \\
\hline Intermediate professional & $39 \%$ \\
\hline Employees & $19.9 \%$ \\
\hline Employed & $80.6 \%$ \\
\hline$\geq 35$ hours a week & $90.5 \%$ \\
\hline \multicolumn{2}{|l|}{ Pregnancy } \\
\hline Planned & $84 \%$ \\
\hline Happily welcomed & $82.6 \%$ \\
\hline \multicolumn{2}{|l|}{ Obstetric complication } \\
\hline Complicated or urgent C-section & $8.7 \%$ \\
\hline Prematurity (>30 days) & $0 \%$ \\
\hline Underweight (<2kg) & $0 \%$ \\
\hline Incubator (>4 weeks) & $0 \%$ \\
\hline
\end{tabular}


Table 2. Factor Structure Regarding EPDS Data (T1, Late Pregnancy)

\begin{tabular}{|c|c|c|c|c|c|c|}
\hline & \multirow{2}{*}{$\begin{array}{c}1 \text { Factor } \\
\text { Dep }\end{array}$} & \multicolumn{2}{|c|}{2 Factors } & \multicolumn{3}{|c|}{3 Factors } \\
\hline & & Dep & Anx & Dep & Anh & Anx \\
\hline Item 1 . Able to laugh & .60 & .66 & -.06 & .01 & $1.06^{\mathrm{d}}$ & .00 \\
\hline Item 2. Enjoyment to things & .60 & .51 & .15 & .29 & .29 & .21 \\
\hline Item 3. Blamed myself & .53 & .43 & .17 & .60 & -.16 & .12 \\
\hline Item 4 . Been anxious & .42 & -.04 & .75 & -.06 & .01 & .86 \\
\hline Item 5. Felt scared & .50 & .07 & .70 & .21 & -.04 & .58 \\
\hline Item 6. Getting on top of me & .52 & .43 & .14 & .37 & .11 & .13 \\
\hline Item 7. Difficulty sleeping & .74 & .79 & -.04 & .85 & -.02 & -.07 \\
\hline Item 8 . Felt sad & .84 & .82 & .06 & .63 & .22 & .13 \\
\hline Item 9. Crying & .70 & .76 & -.06 & .72 & .07 & -.04 \\
\hline Item 10. Harming myself & .29 & .24 & .08 & .34 & -.11 & .06 \\
\hline Alpha $^{a}$ & $.83^{\mathrm{b}}$ & .84 & .71 & .81 & $--^{c}$ & .71 \\
\hline VE Factor & $35 \%$ & $31 \%$ & $12 \%$ & $26 \%$ & $14 \%$ & $13 \%$ \\
\hline VE Total & $35 \%$ & & & & $53 \%$ & \\
\hline
\end{tabular}

Note. Suitability to factor analysis was satisfactory $\left(\mathrm{KMO}=.81\right.$ and Bartlett $\left.=\mathrm{X}^{2}(45)=479, \mathrm{p}<.01\right)$

$\mathrm{VE}=$ Variance Explained. Loadings above .40 are in bold

${ }^{a}$ alpha were computed with items having $>.40$ loadings (in bold).

${ }^{\mathrm{b}}$ All items were included (even item 10 despite low loading).

${ }^{\mathrm{c}}$ Alpha can't be computed for one single item.

${ }^{\mathrm{d}}$ Heywood case. 
Table 3. Factor Structure Regarding EPDS Data (T2)

\begin{tabular}{|c|c|c|c|c|c|c|}
\hline & \multirow{2}{*}{$\begin{array}{c}1 \text { Factor } \\
\text { Dep }\end{array}$} & \multicolumn{2}{|c|}{2 Factors } & \multicolumn{3}{|c|}{3 Factors } \\
\hline & & Dep & Anx & Dep & Anx & Stress \\
\hline Item 1. Able to laugh & .52 & .45 & .09 & .32 & -.07 & .38 \\
\hline Item 2. Enjoyment to things & .59 & .61 & .00 & .49 & -.06 & .25 \\
\hline Item 3. Blamed myself & .57 & .05 & .60 & .06 & .46 & .19 \\
\hline Item 4 . Been anxious & .65 & .00 & .76 & .02 & .88 & -.05 \\
\hline Item 5. Felt scared & .63 & -.02 & .75 & .02 & .54 & .24 \\
\hline Item 6. Getting on top of me & .59 & .27 & .37 & .04 & .13 & .65 \\
\hline Item 7. Difficulty sleeping & .56 & .61 & -.03 & .63 & .04 & -.09 \\
\hline Item 8. Felt sad & .84 & .82 & .07 & .74 & .07 & .12 \\
\hline Item 9. Crying & .80 & .88 & -.04 & .92 & .00 & -.06 \\
\hline Item 10 . Harming myself & .38 & .42 & -.03 & .36 & -.01 & .07 \\
\hline Alpha $^{a}$ & $.86^{\mathrm{b}}$ & .80 & .75 & .82 & .75 & $--{ }^{c}$ \\
\hline VE Factor & $39 \%$ & $27 \%$ & $18 \%$ & $25 \%$ & $15 \%$ & $10 \%$ \\
\hline VE Total & $39 \%$ & & & & $50 \%$ & \\
\hline
\end{tabular}

Note. Suitability to factor analysis was satisfactory $\left(\mathrm{KMO}=.87\right.$ and Bartlett $\left.=\mathrm{X}^{2}(45)=493, \mathrm{p}<.01\right)$

$\mathrm{VE}=$ Variance Explained. Loadings above .40 are in bold.

${ }^{\mathrm{a}}$ alpha were computed with items having $>.40$ loadings (in bold).

${ }^{\mathrm{b}}$ All items were included (even item 10 despite low loading).

${ }^{c}$ Alpha can't be computed for one single item. 
Table 4. Factor Structure Regarding EPDS Data (T3, 4 months postpartum)

\begin{tabular}{|c|c|c|c|c|c|c|}
\hline & \multirow{2}{*}{$\begin{array}{c}1 \text { Factor } \\
\text { Dep }\end{array}$} & \multicolumn{2}{|c|}{2 Factors } & \multicolumn{3}{|c|}{3 Factors } \\
\hline & & Dep & Anx & Dep & Anx & Blame \\
\hline Item 1 . Able to laugh & .71 & .67 & .08 & .64 & .15 & -.04 \\
\hline Item 2. Enjoyment to things & .53 & .74 & -.25 & .78 & -.30 & .04 \\
\hline Item 3. Blamed myself & .21 & -.08 & .48 & .03 & .07 & .77 \\
\hline Item 4 . Been anxious & .39 & .02 & .67 & .04 & .55 & .18 \\
\hline Item 5. Felt scared & .46 & .09 & .68 & .06 & .70 & .08 \\
\hline Item 6. Getting on top of me & .39 & .18 & .36 & .17 & .35 & .06 \\
\hline Item 7. Difficulty sleeping & .72 & .65 & .14 & .60 & .29 & -.15 \\
\hline Item 8. Felt sad & .86 & .74 & .22 & .76 & .15 & .13 \\
\hline Item 9. Crying & .68 & .72 & -.01 & .71 & .00 & .02 \\
\hline Item 10. Harming myself & .43 & .54 & -.12 & .47 & .09 & -.27 \\
\hline Alpha $^{a}$ & $.80^{\mathrm{b}}$ & .83 & .70 & .83 & .73 & $--{ }^{c}$ \\
\hline VE Factor & $32 \%$ & $29 \%$ & $15 \%$ & $28 \%$ & $13 \%$ & $8 \%$ \\
\hline VE Total & $32 \%$ & & & & $49 \%$ & \\
\hline
\end{tabular}

Note. Suitability to factor analysis was satisfactory $\left(\mathrm{KMO}=.81\right.$ and Bartlett $\left.=\mathrm{X}^{2}(45)=402, \mathrm{p}<.01\right)$

$\mathrm{VE}=$ Variance Explained. Loadings above .40 are in bold.

${ }^{a}$ alpha were computed with items having $>.40$ loadings (in bold)

${ }^{\mathrm{b}}$ All items were included (even item 3, 4 and 6 despite low loadings)

${ }^{\mathrm{c}}$ Alpha can't be computed for one single item 
Table 5. Descriptive Statistics and Prevalence for Full EPDS and EPDS-3A.

\begin{tabular}{ccccc}
\hline & \multicolumn{2}{c}{ T2 (2 months) } & \multicolumn{2}{c}{ T3 (4 months) } \\
\cline { 2 - 5 } & M (SD) & Prevalence & M (SD) & Prevalence \\
\hline \multirow{2}{*}{ Full EPDS } & $5.82(4.39)$ & $\geq 13: 9.7 \%$ & $4.91(3.72)$ & $\geq 13: 4.2 \%$ \\
& & $\geq 10: 18.1 \%$ & & $\geq 10: 9.7 \%$ \\
EPDS-3A & $2.91(2.09)$ & $\geq 6: 13.2 \%$ & & $\geq 6: 7.6 \%$ \\
& & $\geq 4: 36.1 \%$ & $2.5(1.87)$ & $\geq 4: 25 \%$ \\
Both & --- & $\geq 13+\geq 6: 7.3 \%$ & & $\geq 13+\geq 6: 3.1 \%$ \\
& & $\geq 10+\geq 4: 17.5 \%$ & & $\geq 10+\geq 4: 7.8 \%$
\end{tabular}

Note. Full EPDS (all items) EPDS-3A (items 3, 4 and 5). 
Table 6. Percentage of participants with scores exceeding EPDS-3A cut-off but not EPDS ones.

\begin{tabular}{|c|c|c|c|}
\hline \multirow[b]{2}{*}{ Exceeding } & \multirow[b]{2}{*}{$\begin{array}{l}\text { While Not } \\
\text { Exceeding }\end{array}$} & \multicolumn{2}{|c|}{ Prevalence } \\
\hline & & $\begin{array}{c}\mathrm{T} 2 \\
\text { (2 months) }\end{array}$ & $\begin{array}{c}\mathrm{T} 3 \\
\text { (4 months) }\end{array}$ \\
\hline \multirow{2}{*}{ EPDS-3A $\geq 4$} & Full EPDS $\geq 10$ & $19.7 \%$ & $20.2 \%$ \\
\hline & Full EPDS $\geq 13$ & $27.7 \%$ & $24.8 \%$ \\
\hline \multirow{2}{*}{ EPDS-3A $\geq 6$} & Full EPDS $\geq 10$ & $1.5 \%$ & $3.1 \%$ \\
\hline & Full EPDS $\geq 13$ & $5.8 \%$ & $5.4 \%$ \\
\hline
\end{tabular}

Note. Full EPDS (all items) EPDS-3A (items 3, 4 and 5). 
Figure 1. Scree Plots for T1, T2 and T3 regarding EPDS Data
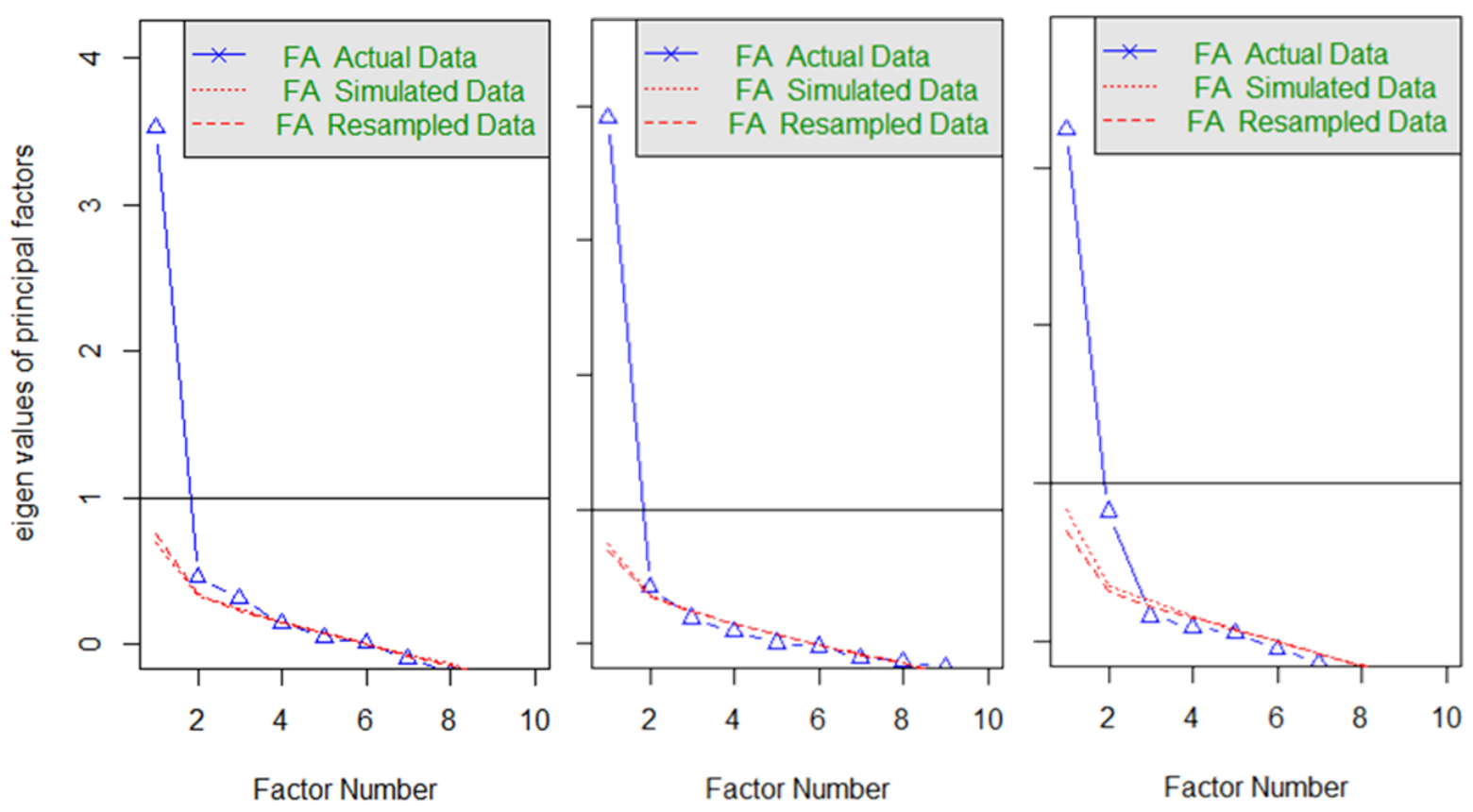

Note. Figure for T1, T2 and T3 are presented to the left, middle and right respectively. 